\title{
Nanostructured polymer blends (P3HT/PMMA): Inorganic titania hybrid photovoltaic devices
}

\author{
Ming-Chung $\mathrm{Wu}^{\mathrm{a}}$, Hsueh-Chung Liao ${ }^{\mathrm{a}}$, Hsi-Hsing Lo ${ }^{\mathrm{a}}$, Sharon Chen ${ }^{\mathrm{a}}$, Yun-Yue Lin ${ }^{\mathrm{a}}$, Wei-Che Yen ${ }^{\mathrm{b}}$, \\ Tsung-Wei Zeng ${ }^{a}$, Chun-Wei Chen ${ }^{a}$, Yang-Fang Chen ${ }^{c}$, Wei-Fang Su ${ }^{\text {a,b,* }}$ \\ ${ }^{a}$ Department of Materials Science and Engineering, National Taiwan University, Taipei 106-17, Taiwan \\ ${ }^{\mathrm{b}}$ Institute of Polymer Science and Enginerring, National Taiwan University, Taipei 106-17, Taiwan \\ c Department of Physics, National Taiwan University, Taipei 106-17, Taiwan
}

\section{A R T I C L E I N F O}

\section{Article history:}

Received 16 December 2007

Accepted 21 November 2008

Available online 23 January 2009

Keywords:

P3HT

PMMA

$\mathrm{TiO}_{2}$

Nanorods

Polymer blend

Heterojunction

\begin{abstract}
A B S T R A C T
We have fabricated a photovoltaic (PV) device based on the polymer blends of (poly(3-hexylthiophene) (P3HT)/polymethylmethacrylate (PMMA)) and inorganic $\mathrm{TiO}_{2}$ nanorod bulk heterojunction. The optimized photovoltaic device with 1.6 wt\% PMMA concentration has a power conversion efficiency of $0.65 \%$ under simulated AM 1.5 illumination $\left(100 \mathrm{~mW} / \mathrm{cm}^{2}\right)$, which is $38 \%$ more efficient than the device without the incorporation of PMMA. Furthermore, the PMMA-included device gives a shortcircuit current density of $2.57 \mathrm{~mA} / \mathrm{cm}^{2}$, an open-circuit voltage of $0.53 \mathrm{~V}$, and a fill factor of 0.48 . Our studies have shown that having optimal PMMA concentration in the photovoltaic devices helps to smoothen the surface of the hybrid thin film, broaden the absorption spectrum, and improve the electrical conductivity. The results implying improvement in cell performance can be illustrated using atomic force microscopy (AFM), a UV/vis spectrophotometer and electrical measurements.
\end{abstract}

(c) 2008 Elsevier B.V. All rights reserved.

\section{Introduction}

Conjugated polymers are often utilized to fabricate large-area, physically flexible, and low-cost solar cells $[1,2]$. A basic requirement for efficient photovoltaic devices is for the free charge carriers, produced upon photoexcitation of the photoactive material, to be transported to the other electrode without recombining with oppositely charged carriers. Photovoltaic devices merely composed of conjugated polymers as the only active material have extremely low electron mobility, and thus limited performance. Recent developments have shown that the use of interpenetrating electron donor-acceptor heterojunctions such as polymer:fullerene [2-4], polymer:polymer [5], and polymer:nanocrystal [6-8] can yield highly efficient photovoltaic conversions.

Titanium dioxide $\left(\mathrm{TiO}_{2}\right)$ nanocrystal is a promising electronaccepting material in organic:inorganic hybrid photovoltaic applications. Several different conjugated polymers have been used in the polymer: $\mathrm{TiO}_{2}$ solar cells, such as poly[2-methoxy5-(2'-ethyl-hexyloxy)-l,4-phenylene vinylene] (MEH-PPV) [9-12], MEH-PPV derivatives [13], poly[2-methoxy-5-(3',7'-dimethyloctyloxy)-1,4-phenylene vinylene] (MDMO-PPV) [14], poly(3-hexylthiophene) (P3HT) [7,15,16], and water-soluble polythiophene [17]. Many scientific approaches fabricate $\mathrm{TiO}_{2}$ photovoltaic

\footnotetext{
* Corresponding author.

E-mail address: suwf@ntu.edu.tw (W.-F. Su).
}

devices by infiltrating polymers into a sintered $\mathrm{TiO}_{2}$ nanoporous thin film. On the other hand, less has been reported on the polymer: $\mathrm{TiO}_{2}$ solar cells made from spin coating a polymer blend: $\mathrm{TiO}_{2}$ nanocrystals solution.

The polymer blend provides a simple, low-cost, and sometimes very effective way to obtain new materials for optoelectronic applications. For example, LEDs [18-20] and photovoltaics (PVs) $[20,21]$, which are made based on a blend of conjugated polymers, are found to be more efficient than those built on one single polymeric material. The deviation comes from the phase separation that takes place in the thin film of the polymer blend. The phase separation creates a series of self-assembled heterojunctions where exciton dissociation (in a PV) or charge recombination (in an LED) can occur more easily.

In this study, we have fabricated a $\mathrm{P} 3 \mathrm{HT} /$ polymethylmethacrylate (PMMA): $\mathrm{TiO}_{2}$ nanorods bulk heterojunction. The device performance is enhanced by adding PMMA into the $\mathrm{P}_{3 \mathrm{HT}} \mathrm{TiO}_{2}$ active layer.

\section{Experimental details}

\subsection{Synthesis of HT-HT poly(3-hexylthiophene) and its characterization}

The HT-HT P3HT was synthesized according to the literature with some modifications [22]. Typically, 2,5-dibromo-3-hexylthiophene 
$(0.030 \mathrm{~mol}, 10 \mathrm{~g})$ was added into a $500 \mathrm{ml}$ three-neck roundbottom flask equipped with a 24/40 ground joint, a reflux condenser, and a magnetic stir-bar, and was purged with dry nitrogen for $15 \mathrm{~min}$. About $320 \mathrm{ml}$ freshly distilled THF was transferred to the flask and the solution was stirred under dry nitrogen. The solution of tert-butylmagnesium chloride in diethyl ether $(0.032 \mathrm{~mol}, 16 \mathrm{ml})$ was added via an airtight syringe and then heated in reflux for $1.5 \mathrm{~h}$. The solution was allowed to cool to room temperature followed by the addition of $\mathrm{Ni}(\mathrm{dppp}) \mathrm{Cl}_{2}$ ( 2 mole\% of monomer, $0.33 \mathrm{~g}$ ), stirring at room temperature for $0.5 \mathrm{~h}$. The solution was poured into methanol $(500 \mathrm{ml})$. This action led to precipitation. The solid was collected in a cellulose extraction thimble and then washed with methanol in a Soxhlet apparatus. The polymer was dried in vacuum overnight and gathered as a dark purple material (60\% yield). The synthesized polymer had an average molecular weight of $M_{\mathrm{w}}=33 \mathrm{kDa}$ with a polydispersity index of 1.19 determined by GPC. The ${ }^{1} \mathrm{H}$ NMR $(400 \mathrm{MHz})$ result gave $\delta 6.98\left(\mathrm{~s},{ }^{1} \mathrm{H}\right), \delta 2.80\left(\mathrm{t},{ }^{2} \mathrm{H}\right), \delta 1.72$ (pentet, $\left.{ }^{2} \mathrm{H}\right), \delta 1.44\left(\mathrm{~m},{ }^{2} \mathrm{H}\right), \delta 1.35\left(\mathrm{~m},{ }^{4} \mathrm{H}\right)$, and $\delta 0.92\left(\mathrm{t},{ }^{3} \mathrm{H}\right)$.

\subsection{Synthesis of $\mathrm{TiO}_{2}$ nanorods and characterization}

The controlled growth of the anatase titanium dioxide nanorods with a high aspect ratio was accomplished by hydrolyzing titanium tetraisopropoxide according to the literature with some modifications [23]. Typically, oleic acid (120 g, Aldrich, 90\%) was stirred vigorously at $120^{\circ} \mathrm{C}$ for $1 \mathrm{~h}$ in a three-neck flask under Ar flow, then allowed to cool to $90{ }^{\circ} \mathrm{C}$, and maintained at the temperature. Titanium isopropoxide ( $17 \mathrm{mmol}$, Aldrich, 99.999\%) was added into the flask. After stirring for $5 \mathrm{~min}$, trimethylamine$\mathrm{N}$-oxide dehydrate ( $34 \mathrm{mmol}$, ACROS, 98\%) in $17.0 \mathrm{ml}$ water was rapidly injected. Trimethylamine-N-oxide dihydrate was used as a catalyst for polycondensation. This reaction was continued for $9 \mathrm{~h}$ to have a complete hydrolysis and crystallization process. Subsequently, the $\mathrm{TiO}_{2}$ nanorods product was then obtained ( $4 \mathrm{~nm}$ in diameter, $20-40 \mathrm{~nm}$ in length). The nanorods were washed and precipitated using ethanol repeatedly to remove any residual surfactant. Finally, the $\mathrm{TiO}_{2}$ nanorods were collected by centrifugation and then re-dispersed in chloroform. The crystalline structure of the $\mathrm{TiO}_{2}$ nanorods was studied using X-ray diffraction (XRD) (Philips PW3040 with filtered $\mathrm{Cu} \mathrm{K} \alpha$ radiation $(\lambda=1.540 \AA)$ ). The analysis of the nanorods was performed using a JOEL JEM-1230 transmission electron microscope (TEM) operating at $120 \mathrm{keV}$ or a $2000 \mathrm{FX}$ high-resolution transmission electron microscope (HRTEM) at $200 \mathrm{keV}$.

\subsection{Fabrication of the nanostructure polymer blends/inorganic titania hybrid photovoltaic devices}

The indium-tin-oxide (ITO)/poly(3,4-ethylenedioxythiophene)-poly(styrenesulfonate) (PEDOT:PSS)/poly(3-hexylthiophene): $\mathrm{TiO}_{2}$ nanorods/Al device was fabricated in the following manner. An ITO glass substrate with a sheet resistance of $15 \Omega$ / square (Merck) was ultrasonically cleaned in a series of organic solvents (ethanol, methanol, and acetone). A 60-nm-thick layer of PEDOT:PSS (Aldrich) was spin-casted onto the ITO substrate at $300 \mathrm{rpm}$ for $10 \mathrm{~s}$ and at $6000 \mathrm{rpm}$ for $1 \mathrm{~min}$, consecutively. $\mathrm{TiO}_{2}$ nanorods dispersed in the pyridine-chloroform solvent (weight ratios pyridine:chloroform $=2: 7$ ) and $\mathrm{P} 3 \mathrm{HT}$ in chlorobenzene were thoroughly mixed and spin-cast on top of the PEDOT:PSS layer (weight ratios $\mathrm{TiO}_{2}: \mathrm{P}_{3} \mathrm{HT}=47: 53$ ). The thickness of the P3HT/PMMA: $\mathrm{TiO}_{2}$ nanorods film was $100 \mathrm{~nm}$ after $1000 \mathrm{rpm}$ rotation for a minute. Then, the $100 \mathrm{~nm}$ Al electrode layer was vacuum-deposited on the hybrid material. By inserting the $\mathrm{TiO}_{2}$ nanorods thin film between the $\mathrm{P} 3 \mathrm{HT} / \mathrm{PMMA}: \mathrm{TiO}_{2}$ nanorods hybrid and the $\mathrm{Al}$ electrode, the modified device with a configuration of ITO/PEDOT:PSS/ (P3HT/PMMA): $\mathrm{TiO}_{2}$ nanorods/ Al was created.

\subsection{Physical properties measurement of the nanostructure polymer} blends/inorganic titania hybrid photovoltaic devices

The current-voltage $(I-V)$ characterization (Keithley 2400 source meter) was performed under $10^{-3}$ Torr vacuum, with monochromatic illumination at a defined beam size (Oriel, Inc.) The Air Mass (AM) 1.5 condition was measured using a calibrated solar simulator (Oriel, Inc.) at an irradiation intensity of $100 \mathrm{~mW} /$ $\mathrm{cm}^{-2}$. Once the power from the simulator was determined, a $400 \mathrm{~nm}$ cut-off filter was used to remove the UV light. The film thickness was determined by an $\alpha$-stepper (DEKTAK 6 M 24383) and the morphology was observed using atomic force microscopy (AFM) (Digital Instruments Nanoscope III). The $120 \mathrm{~nm}$ P3HT and P3HT/PMMA:TiO 2 nanorod hybrid films were cast on a quartz substrate and sent to obtain UV-visible absorption (Perkin-Elmer Lambda 35) measurements. The electrical conductivity of the P3HT and P3HT/PMMA: $\mathrm{TiO}_{2}$ nanorod hybrid films was measured by a source meter (Keithley 2400 source meter) using a four-point probe method.

\section{Results and discussion}

The TEM image of $\mathrm{TiO}_{2}$ nanorods in the inset of Fig. 1 reveals that the dimensions of the $\mathrm{TiO}_{2}$ nanorods are $20-30 \mathrm{~nm}$ in length and $4-5 \mathrm{~nm}$ in diameter. The high-resolution TEM image of the $\mathrm{TiO}_{2}$ nanorods is shown in Fig. 1. The above inset image shows the HRTEM image of $\mathrm{TiO}_{2}$ nanorods crystallinity, and the corresponding selected-area diffraction pattern of the $\mathrm{TiO}_{2}$ nanorods is shown in the below inset of Fig. 1 . The $d$-spacing of this ring pattern is $3.54,2.39,1.90$, and $1.69 \AA$ from the inner ring to the outer ring. It can be indexed for (101), (0 0 4), (2 00$)$, and (211) of the $\mathrm{TiO}_{2}$ anatase phase, consistent with the XRD result. The filtered image from the square region is also shown, which

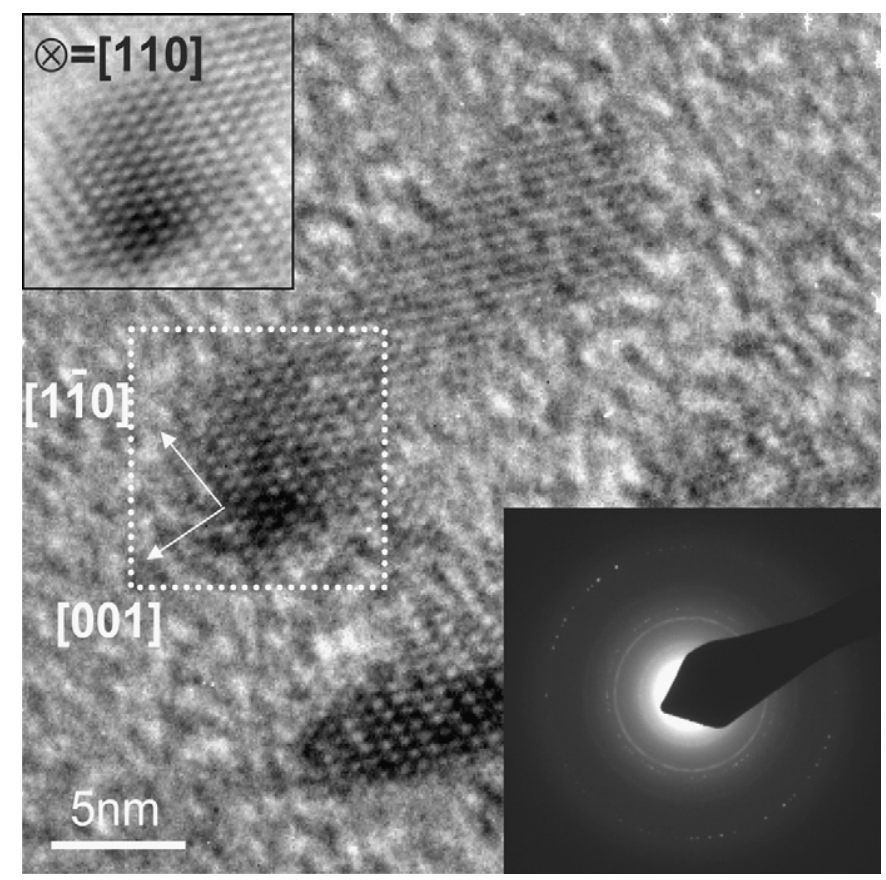

Fig. 1. Transmission electron microscope image of anatase $\mathrm{TiO}_{2}$ nanorods 
indicates that the growth direction of the $\mathrm{TiO}_{2}$ nanorods is along the longitudinal [0 01] direction in the synthesized condition.

To set a baseline for comparison purposes, we made a standard hybrid device structure similar to the polymer:nanocrystal photovoltaic devices reported previously. This device was chosen because its external quantum efficiency could reach the order up to $10 \%$. A schematic diagram of our standard device configuration is shown in Fig. 2, which consists of a transparent indium-tinoxide conducting electrode, poly(3,4-ethylenedioxythiophene)poly(styrenesulfonate) $\mathrm{P} 3 \mathrm{HT} / \mathrm{PMMA}$ blends: $\mathrm{TiO}_{2}$ nanorods hybrid film, and an aluminium (Al) electrode.

The current-voltage curves for the four devices with different PMMA concentrations from $0 \mathrm{wt} \%$ (square symbol), $1.6 \mathrm{wt} \%$ (circinate symbol), $3.2 \mathrm{w} \%$ (triangular symbol) to $11.7 \mathrm{w} \%$ (rhombic symbol), with or without illumination, are shown in Fig. 3. After adding a PMMA concentration of $1.6 \mathrm{wt} \%$ in weight ratio (red curve), the short-circuit current increases slightly from 2.13 to $2.57 \mathrm{~mA} / \mathrm{cm}^{2}$ and the filled factor increases from $43.31 \%$ to $48.31 \%$, which is the highest filled factors among the four devices. The open-circuit voltage also changed slightly after PMMA addition. Table 1 summarizes the performance of various photovoltaic devices fabricated in this work

In order to fully understand the effect of PMMA in the P3HT/ $\mathrm{TiO}_{2}$ nanorods photovoltaic devices, we studied the hybrid film morphology using AFM. We have found that PMMA helped to promote the quality and smoothness of the fabricated film. Fig. 4 shows the pairs of the AFM topography and the phase images of

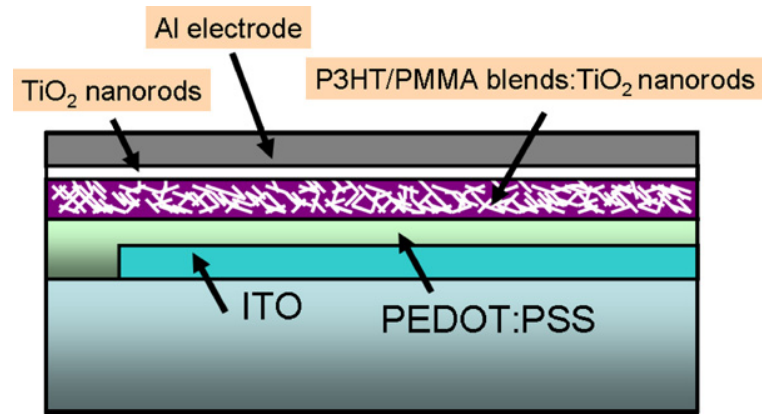

Fig. 2. The schematic structure of standard configuration P3HT/PMMA blend$\mathrm{s}: \mathrm{TiO}_{2}$ nanorods hybrid photovoltaic devices.

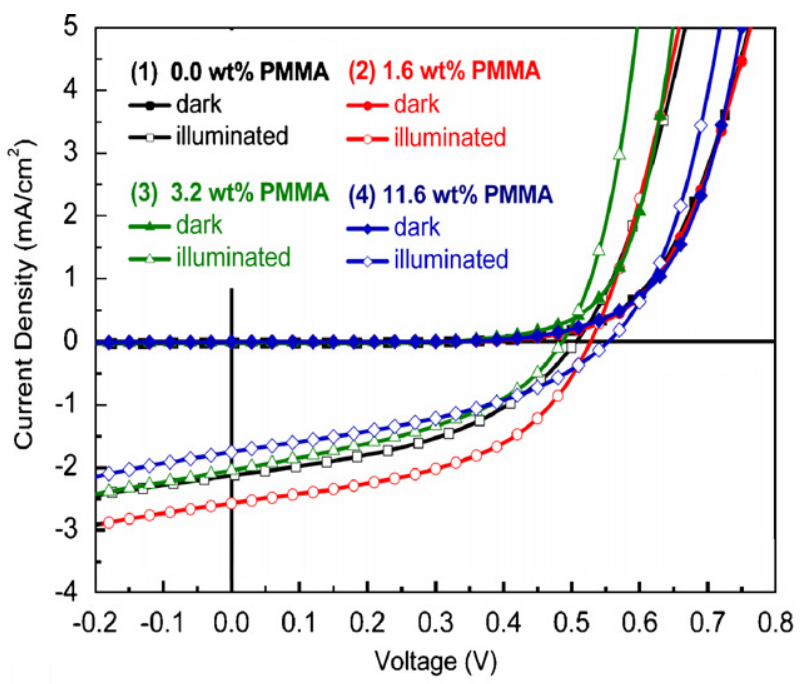

Fig. 3. $I-V$ characteristic of photovoltaic cells with different PMMA concentrations under AM 1.5 illumination. The PMMA concentrations in the devices were $0 \mathrm{wt} \%$ (square symbol), $1.6 \mathrm{wt} \%$ (circinate symbol), $3.2 \mathrm{wt} \%$ (triangular symbol), and $11.7 \mathrm{wt} \%$ (rhombic symbol) in weight ratio.
P3HT/PMMA: $\mathrm{TiO}_{2}$ nanorod hybrids with different PMMA concentrations. The PMMA weight percentages of P3HT/PMMA:TiO nanorods are $0,1.6,3.2$, and 11.6 . The $\mathrm{TiO}_{2}$ nanorods are randomly

Table 1

Summary of the device performance for various $\mathrm{P}_{3} \mathrm{HT}: \mathrm{TiO}_{2}$ nanorods hybrid photovoltaic devices with different PMMA concentrations under AM 1.5 illumination $\left(100 \mathrm{~mW} / \mathrm{cm}^{2}\right)$.

\begin{tabular}{llllll}
\hline No. & $\begin{array}{l}\text { PMMA } \\
\text { concentration } \\
(\text { wt\% })\end{array}$ & $V_{\mathrm{oc}}(\mathrm{V})$ & $\begin{array}{l}I_{\mathrm{sc}}(\mathrm{mA} / \\
\left.\mathrm{cm}^{2}\right)\end{array}$ & $\mathrm{FF}(\%)$ & $\begin{array}{l}\text { Power } \\
\text { conversion } \\
\text { efficiency (\%) }\end{array}$ \\
\hline 1 & 0.0 & 0.51 & 2.13 & 43.31 & 0.47 \\
2 & 1.6 & 0.53 & 2.57 & 48.31 & 0.65 \\
3 & 3.2 & 0.49 & 2.05 & 40.79 & 0.41 \\
4 & 11.6 & 0.55 & 1.76 & 39.28 & 0.38 \\
\hline
\end{tabular}
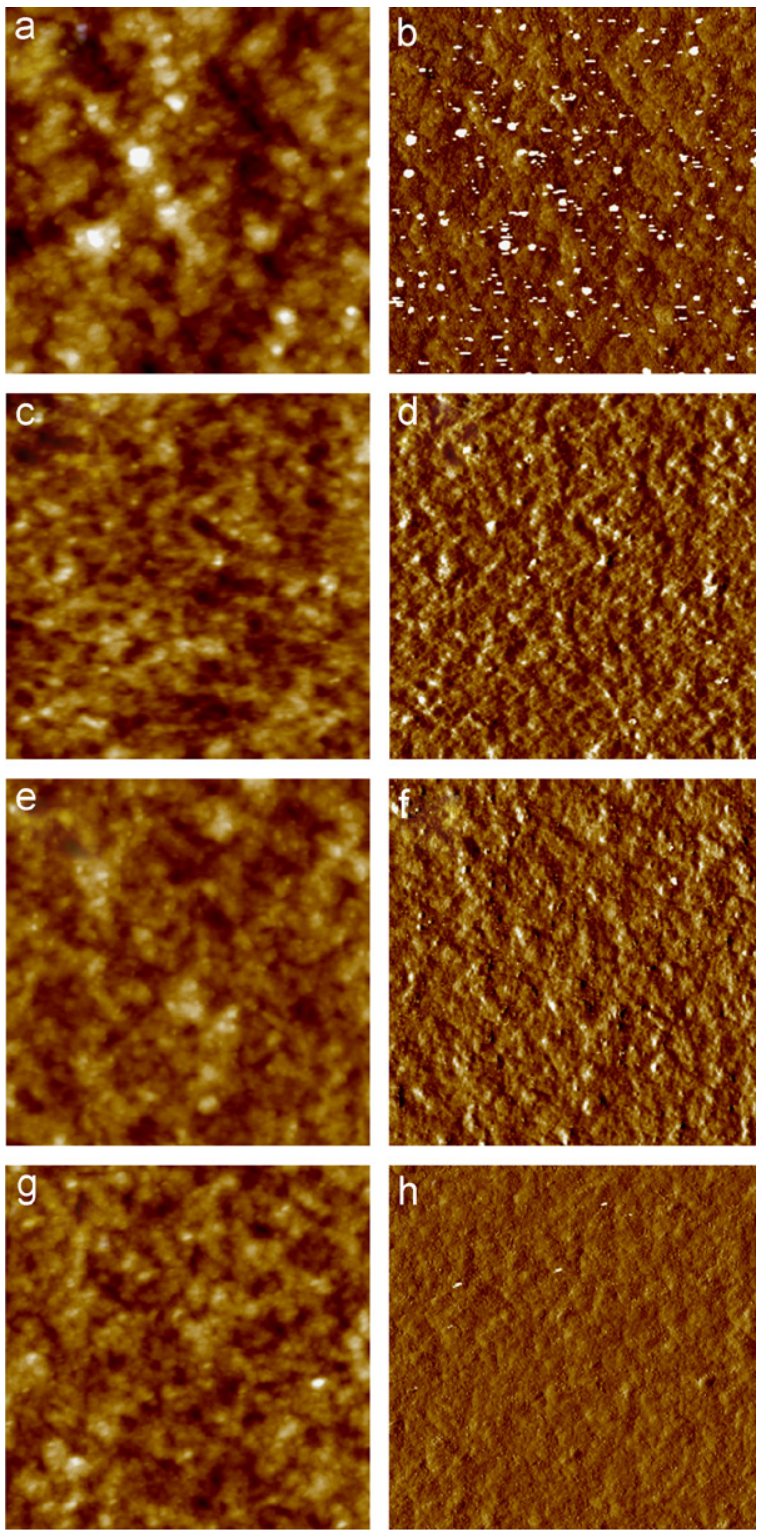

$0 \mathrm{~nm}$

$100 \mathrm{~nm} 0^{\circ}$

$100^{\circ}$

Fig. 4. AFM images of the surface morphology of $\mathrm{P} 3 \mathrm{HT} / \mathrm{PMMA}: \mathrm{TiO}_{2}$ nanorod hybrid films with different concentrations of PMMA. The PMMA concentrations in the film are (a,b) $0.0 \mathrm{wt} \%$, (c,d) $1.6 \mathrm{wt} \%$, (e,f) $3.2 \mathrm{wt} \%$, and (g,h) $11.6 \mathrm{wt} \%$, respectively. 
distributed in the polymer matrix to form an interconnecting network. The tapping mode of AFM can provide a phase image of the thin film, because a rigid material generally shows a positive phase shift with respect to a soft material due to the cantilever oscillation being related to the power dissipated in a nonelastic tip-sample interaction [7]. The bright areas are interpreted as $\mathrm{TiO}_{2}$ nanorod rigid materials and the darker areas as polymer soft materials. The root-mean-square roughness of the surface morphology of the thin film decreases with increasing PMMA concentrations as shown in Table 2.

In order to further understand the changes of optical properties at different PMMA concentrations in the hybrid film, we measured their absorption spectra. The results are shown in Fig. 5. The optical density and the full-width at half-maximum of the absorption peaks in the hybrid film are increased gradually with increasing PMMA concentrations. For most binary polymer blends, the entropy change of mixing is small, so the enthalpic factor becomes dominant. Unfavorable enthalpic interaction leads to nanoscale phase separation in polymer blends. In the blend of P3HT and PMMA, the PMMA effectively suppresses the energy transfer between the conjugated polymer P3HT. The $\pi$ electron is well-localized and hops in a mechanism similar to the oligomer P3HT rather than delocalized as in the P3HT polymer. Hence, the suppressed electron motion causes the effective conjugated length to be reduced and results in an enlarged band gap according to the quantum well approximation. Consequently, a broad and enhanced light absorption was observed by the addition of PMMA into the hybrid composition. We have used a

\section{Table 2}

Summary of physical properties and the device performance for various P3HT/ $\mathrm{PMMA}_{\mathrm{TiO}}{ }_{2}$ nanorods hybrid photovoltaic devices under AM 1.5 illumination $\left(100 \mathrm{~mW} / \mathrm{cm}^{2}\right)$.

\begin{tabular}{lllll}
\hline No. & $\begin{array}{l}\text { PMMA } \\
\text { concentration } \\
(\text { wt\%) }\end{array}$ & $\begin{array}{l}\text { Root-mean- } \\
\text { square } \\
\text { roughness } \\
(\mathrm{nm})\end{array}$ & $\begin{array}{l}\text { Conductivity } \\
(\mathrm{S} / \mathrm{cm})\end{array}$ & $\begin{array}{l}\text { Power } \\
\text { conversion } \\
\text { efficiency (\%) }\end{array}$ \\
\hline A & 0.0 & 3.85 & $5.75 \times 10^{-5}$ & 0.47 \\
B & 1.6 & 3.31 & $6.81 \times 10^{-5}$ & 0.65 \\
C & 3.2 & 3.18 & $5.72 \times 10^{-5}$ & 0.41 \\
D & 11.6 & 2.74 & $4.30 \times 10^{-5}$ & 0.38 \\
\hline
\end{tabular}

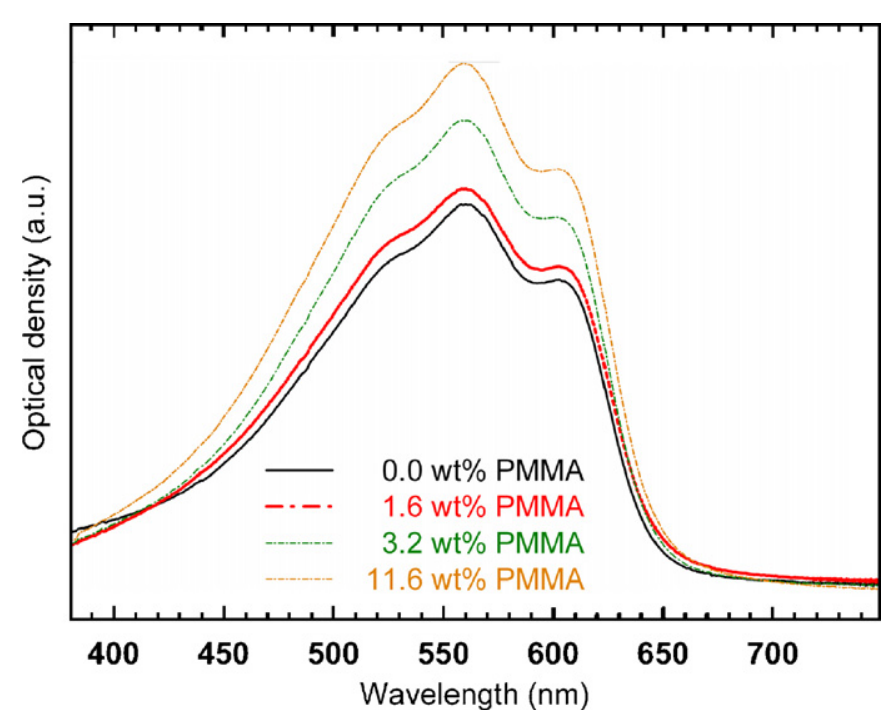

Fig. 5. Absorption spectra of $\mathrm{P} 3 \mathrm{HT} / \mathrm{PMMA}: \mathrm{TiO}_{2}$ nanorod hybrid films with different concentrations of PMMA. four-point probe to measure the conductivity of the hybrid film containing different concentrations of PMMA. The addition of PMMA in the hybrid promotes the formation of a smooth film with reduced defects such as voids, and improves the conductivity of the hybrid film at a low concentration of $1.6 \mathrm{wt} \%$. However, at a concentration higher than $1.6 \mathrm{wt} \%$, the insulating characeteristics of PMMA take over the smoothness effect and the film becomes less conductive; thus the efficiency of the devices decreases. The results are summarized in Table 2.

\section{Conclusions}

We have fabricated photovoltaic devices using a new type hybrid material consisting a polymer blend (P3HT/PMMA) and $\mathrm{TiO}_{2}$ nanorods. The addition of PMMA in the hybrid material can smoothen the film surface morphology, reduce the occurrence of air pores and defects, and enhance light absorption. A small amount of PMMA ( $\sim 1.6$ wt\%) enhances the electrical conductivity, thus improving the performance of photovoltaic devices. More than $38 \%$ device efficiency has been observed as compared with the device without the incorporation of PMMA.

\section{Acknowledgements}

The financial support from the National Science Council of Taiwan (NSC-96-2628-E-002-017-MY3 and NSC 95-3114-P-002003-MY3) is highly appreciated. The authors would also like to thank Prof. K.C. Cheng, Prof. C.F. Lin, and Dr. F.C. Hsu of National Taiwan University for helpful discussions.

\section{References}

[1] W.U. Huynh, J.J. Dittmer, A.P. Alivisatos, Hybrid nanorod-polymer solar cell shybrid nanorod-polymer solar cells, Science 295 (2002) 2425.

[2] W. Ma, C. Yang, X. Gong, K. Lee, A.J. Heeger, Thermally stable, efficient polymer solar cells with nanoscale control of the interpenetrating network morphology, Adv. Funct. Mater. 15 (2005) 1617.

[3] S.E. Shaheen, C.J. Brabec, N.S. Sariciftci, F. Padiner, T. Fromherz, J.C. Hummelen, 2.5\% efficient organic plastic solar cells, Appl. Phys. Lett. 78 (2001) 841.

[4] X. Yang, J. Loos, S.C. Veenstra, W.J.H. Verhees, M.M. Wienk, J.M. Kroon, M.A.J. Michels, R.A.J. Janssen, Nanoscale morphology of high-performance polymer solar cells, Nano Lett. 5 (2005) 579.

[5] M. Granström, K. Petritsch, A.C. Arias, A. Lux, M.R. Andersson, R.H. Friend, Laminated fabrication of polymeric photovoltaic diodes, Nature 395 (1998) 257.

[6] W.J.E. Beek, M.M. Wienk, M. Kemerink, X. Yang, R.A.J. Janssen, Computer simulations of the refolding of sperm whale apomyoglobin from hightemperature denaturated state, J. Phys. Chem. B 109 (2005) 9505.

[7] C.Y. Kwong, W.C.H. Choy, A.B. Djurišic, P.C. Chui, K.W. Cheng, W.K. Chan, Poly(3-hexylthiophene): $\mathrm{TiO}_{2}$ nanocomposites for solar cell applications, Nanotechnology 15 (2004) 1156.

[8] Y.Y. Lin, C.W. Chen, J. Chang, T.Y. Lin, I.S. Liu, W.F. Su, Exciton dissociation and migration in enhanced order conjugated polymer/nanoparticle hybrid materials, Nanotechnology 17 (2006) 1260.

[9] Q. Fan, B. McQuillin, D.D.C. Bradley, S. Whitelegg, A.B. Seddon, A solid state solar cell using sol-gel processed material and a polymer, Chem. Phys. Lett. 347 (2000) 325.

[10] H. Wang, C.C. Oey, A.B. Djurišic, K.K.Y. Man, W.K. Chan, M.H. Xie, Y.H. Leung P.C. Chui, A. Pandey, J.M. Nunzi, Titania bicontinuous network structures for solar cell applications, Appl. Phys. Lett. 87 (2005) 023507.

[11] Y.T. Lin, T.W. Zeng, W.Z. Lai, C.W. Chen, Y.Y. Lin, Y.S. Chang, W.F. Su, Efficient photoinduced charge transfer in $\mathrm{TiO}_{2}$ nanorod/conjugated polymer hybrid materials, Nanotechnology 17 (2006) 5781.

[12] T.-W. Zeng, Y.-Y. Lin, C.-W. Chen, W.-F. Su, C.-H. Chen, S.-C. Liou, H.-Y. Huang, A large interconnecting network within hybrid $\mathrm{MEH}-\mathrm{PPV} / \mathrm{TiO}_{2}$ nanorod photovoltaic devices, Nanotechnology 17 (2006) 5387.

[13] R. Ravirajan, D.D.C. Bradley, J. Nelson, S.A. Haque, J.R. Durrant, H.J.P. Smith, J.M. Kroon, Efficient charge collection in hybrid polymer $/ \mathrm{TiO}_{2}$ solar cells using poly (ethylenedioxythiophene)/polystyrene sulphonate as hole collector, Appl. Phys. Lett. 86 (2005) 143101.

[14] P.A. Van Hal, M.M. Wienk, J.M. Kroon, W.J. Verhees, L.H. Sloof, W.J.H. Van Gennip, P. Jonkheijm, R.A.J. Janssen, Photoinduced electron transfer and photovoltaic response of a MDMO-PPV: $\mathrm{TiO}_{2}$ bulk-heterojunction, Adv. Mater. 15 (2003) 118. 
[15] K.M. Coakley, M.D. McGehee, Nanoindentation of silicon nitride: a multimillion-atom molecular dynamics study, Appl. Phys. Lett. 83 (2003) 3380.

[16] Y. Liu, M.A. Summers, C. Edder, J.M.J. Fr'echet, M.D. McGehee, Using resonance energy transfer to improve exciton harvesting in organic-inorganic hybrid photovoltaic cells, Adv. Mater. 17 (2005) 2960.

[17] Q. Qiao, J.T. McLeskey, Water-soluble polythiophene/nanocrystalline $\mathrm{TiO}_{2}$ solar cells, Appl. Phys. Lett. 86 (2005) 153501.

[18] J. Jiang, Y. Xu, W. Yang, R. Guan, Z. Liu, H. Zhen, Y. Cao, High-efficiency whitelight-emitting devices from a single polymer by mixing singlet and triplet emission, Adv. Mater. 18 (2006) 1769.

[19] N.A. Iyengar, B. Harrison, R.S. Duran, K.S. Schanze, J.R. Reynolds, Morphology evolution in nanoscale light-emitting domains in MEH-PPV/PMMA blends Macromolecules 36 (2003) 8978.
[20] J. Luo, X. Li, Q. Hou, J. Peng, W. Yang, Y. Cao, High-efficiency white-light emission from a single copolymer: fluorescent blue, green, and red chromophores on a conjugated polymer backbone, Adv. Mater. 19 (2007) 1113.

[21] Y.G. Kim, B.C. Thompson, N. Ananthakrishnan, G. Padmanaban, Variable band gap conjugated polymers for optoelectronic and redox application, J. Mater. Res. 20 (2005) 3188.

[22] R.S. Loewe, S.M. Khersonsky, R.D. McCullough, A simple method to prepare head-to-tail coupled, regioregular poly(3-alkylthiophenes) using grignard metathesis, Adv. Mater. 11 (1999) 250.

[23] P.D. Cozzoli, A. Kornowski, H. Weller, Low-temperature synthesis of soluble and processable organic-capped anatase $\mathrm{TiO}_{2}$ nanorods, J. Am. Chem. Soc. 125 (2003) 14539. 